Ethiopian Journal of Environmental Studies \& Management 8(6): 628 - 634, 2015.

ISSN:1998-0507

doi: http://dx.doi.org/10.4314/ejesm.v8i6.2

Submitted: December 04, 2014

Accepted: August 07, 2015

\title{
QUANTITATIVE INDICES TO MEASURE UNIT CHANNEL BAR LOCATION: A THEORETICAL AND EMPIRICAL STUDY
}

\author{
*AZNARUL, I. ${ }^{1}$ AND BALAI, C.D. ${ }^{2}$ \\ ${ }^{1}$ Department of Geography, Barasat Government College, Kolkata-700124, West Bengal, \\ India \\ ${ }^{2}$ Department of Geography, Krishnagar Government College, West Bengal, Nadia-741101, \\ India
}

\begin{abstract}
Each and every channel bar possesses a specific location within a channel. The terms midchannel bar, bank attached bar are lacking quantitative definition. The intention of formulation of the two indices is to measure the channel bar location on strict quantitative basis. These indices will precisely determine the location of the mid-channel bar and bank attached bar. The first measure will determine the physical location, considering only distance and the second one will be for determining virtual or relative location considering both distance and hydrologic parameters mainly discharge.
\end{abstract}

Key Word: Physical location; Virtual location, Mid-channel bar, Bank attached bar

\section{Introduction}

Channel bar is the accumulation of deposited sediment within the channel. It begins once the flow velocity falls below the settling velocity of a particle, which obstructs the entrainment process (PrusChacinski, 1954; Leopold, Wolman, Miller, 1964; Knighton, 1984). Formation of channel bar is common for the channel having the presence of skew-induced secondary flow (Richards, 1982). Naturally meandering and braided rivers display ideal condition for bar formation. Meandering channel often displays unit bar while the braided channel (multi-thread channel) the compound bar (Smith, 1974). Perhaps Leopold and Wolman (1957) have first demonstrated the successive evolution of central channel bar formation in laboratory flume for the braided river condition. Later, Ashmore (1982, 1991), Thorne et al. (1993), Bristow and Best (1993), Ashworth (1996), Ashworth et al. (2000) have developed the model of mid channel bar evolution and their hydro-morphological characteristics. Perhaps all the previous works on the channel bar have focussed on formation, development, morphological characteristics and the typology of bar. There are two broad categories of bars- unit bar and compound bar (Smith, 1974). Unit bar is one where only one united bar is bifurcating the channel and compound bar is consisted of a number bars making a braided or multi-thread channel. What is most lacking is the quantitative definition of mid channel bar and bank attached bar. The intention of the present paper is to formulate two indices on unit channel bar location which will define mid channel bar and bank attached bar on strict quantitative basis. Indices, in this paper, will be useful for determining the unit channel bar location in meandering rivers and the nature and evolution of primary and secondary flow of the channels also. 


\section{Methodology}

On unit channel bar location no previous quantitative indices have been noted. The existence of Ripple asymmetry index (Tanner, 1967; Reineck and Wunderlich, 1968) and channel asymmetry index (Knighton, 1981) gives some indications for formulation of quantitative indices on unit channel bar location. An index of asymmetry should as far as possible fulfil certain basic requirements (Knighton, 1981).

1. Extreme asymmetry should be expressed by the value ' 1 ' and

2. No asymmetry should be expressed by the value ' 0 '

This principle of asymmetry indices has been embraced for unit channel bar location.

In nature perfect or symmetric mid channel bar is rare. More than $90 \%$ bars are either left skewed or right skewed. Even if a bar originates as a perfect or symmetric mid channel bar it will be skewed in the long run because of the presence of skewed induced secondary flow regime in the meandering channel. How far a bar is perfect mid-channel or how much proportion it is deviated or skewed from the perfect mid-channel bar condition, a quantitative dimension is essential. To meet this current need the two simple indices have been formulated. These indices have been derived through the application of simple principles of geometry and trigonometry and some hydro-geomorphic principles.

The first measure in this paper is the ratio of width difference of channel and bar $\left(\mathrm{W}_{\mathrm{d}}\right)$ to total channel width $(\mathrm{W})$. For defining $\mathrm{W}_{\mathrm{d}}$, difference between width of the left channel $\left(\mathrm{W}_{1}\right)$ with reference to bar centroid and width of the right channel $\left(\mathrm{W}_{\mathrm{r}}\right)$ with reference to bar centroid was calculated (Fig. 1).Total channel width (W) was defined as shortest distance between high bank to brinkpoint of levee (Das and Islam, 2015).

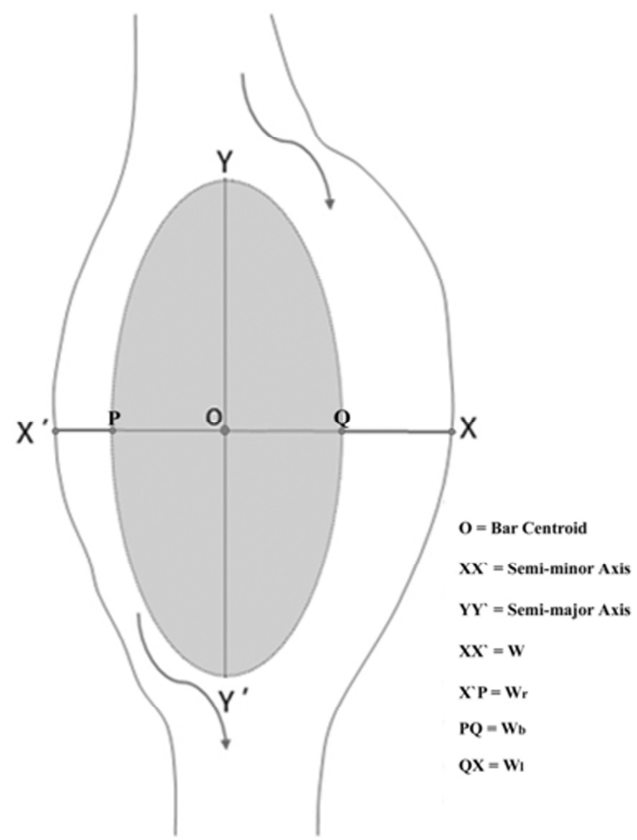

Fig. 1: Definition of parameters of a midchannel bar

Now the $\mathrm{L}_{\mathrm{b}} 1$ can be derived as in the equation number 1 . The sign ' \pm 'in this equation, after closing of first bracket, is to be considered as ' + 'if difference in channel width $\left(\mathrm{W}_{\mathrm{l}}-\mathrm{W}_{\mathrm{r}}\right)$ appears as positive, and as ', if difference in channel width $\left(\mathrm{W}_{1}-\mathrm{W}_{\mathrm{r}}\right)$ appears as negative for final determination of $\mathrm{W}_{\mathrm{d}}$.

$L_{b} \mathbf{1}=\frac{w d}{w}=\frac{(w l-w r) \pm w b}{w}$

$\left(\mathrm{L}_{\mathrm{b}} 1=\right.$ physical location of channel bar)

The first measure $\left(\mathrm{L}_{\mathrm{b}} 1\right)$ will determine the physical location of bar. For this index, value ' 0 ' indicates perfect mid-channel bar, value ' 1 ' indicates perfect bank attached bar and values in between $>0$ and $<1$ indicates the transitional types. The ' + ' signs indicate the right bank orientation of the unit channel bar and the '-' sign indicates the left bank orientation of the bar. In reality it is often true that, the bar is closer to the right bank and lion share of flow is also through the narrow right channel. In such case, although physically the bar is right bank oriented, yet it seems that the flow 
pattern of the river has pushed the bar virtually towards left bank. Same case may happen for the left bank oriented bar also. That is why; weightage of discharge percentages has been taken into consideration for the derivation of second measure.

$\mathbf{Q}_{b}=\frac{\mathrm{Q} \mathbf{l}-\mathrm{Q} \mathbf{r}}{\mathbf{0}}$

Where, $\mathrm{Q}_{\mathrm{b}}=$ virtual location of the channel bar in terms of variation in discharge through different channel

Q1 = discharge through left channel

Qr = discharge through left channel and

$\mathrm{Q}=$ total discharge.

The intention of the second measure is the determination of the virtual location of the unit channel bar in place of physical location. But location of mid channel bar is neither exclusively a matter of physical location nor exclusively a matter of virtual location in terms of discharge variation. Both are equally important for considering the location of the mid channel bar. That is why, on next step (equation 3), for deriving the virtual location of the bar, $\mathrm{L}_{b} 1$ has been extended considering discharge of the left channel $\left(\mathrm{Q}_{1}\right)$ and discharge of the right channel $\left(\mathrm{Q}_{\mathrm{r}}\right)$ and total discharge $(\mathrm{Q})$ in the following manner.

$$
\begin{aligned}
& \mathrm{L}_{\mathrm{b}} 2=0.5\left(\mathrm{~L}_{\mathrm{b}} 1+\mathrm{Q}_{\mathrm{b}}\right) \\
& \mathrm{Or}, \\
& \boldsymbol{L}_{b} \mathbf{2}=\mathbf{0 . 5}\left(\frac{(\mathbf{w l}-\mathbf{w r}) \pm \mathbf{w b}}{\mathbf{w}}+\frac{\mathrm{ql}-\mathrm{or}}{\mathbf{e}}\right\}
\end{aligned}
$$

In the index $\mathrm{L}_{\mathrm{b}} 2$, value ' 0 ' indicates perfect mid-channel bar, value 1 indicates perfect bank attached bar and values in between ' 0 ' and ' 1 ' indicates the transitional types. The ' + ' sign indicate the right bank orientation of the unit channel bar and the '-' sign indicates the left orientation of the unit channel bar.

For empirical analysis of the location of the unit channel bar, 16 unit channel bars on the River Bhagirathi, India have been selected (Fig. 2). Data on the $\mathrm{L}_{\mathrm{b}} 1$ have been collected with the help of Google Earth Professional Software from these 16 bars.

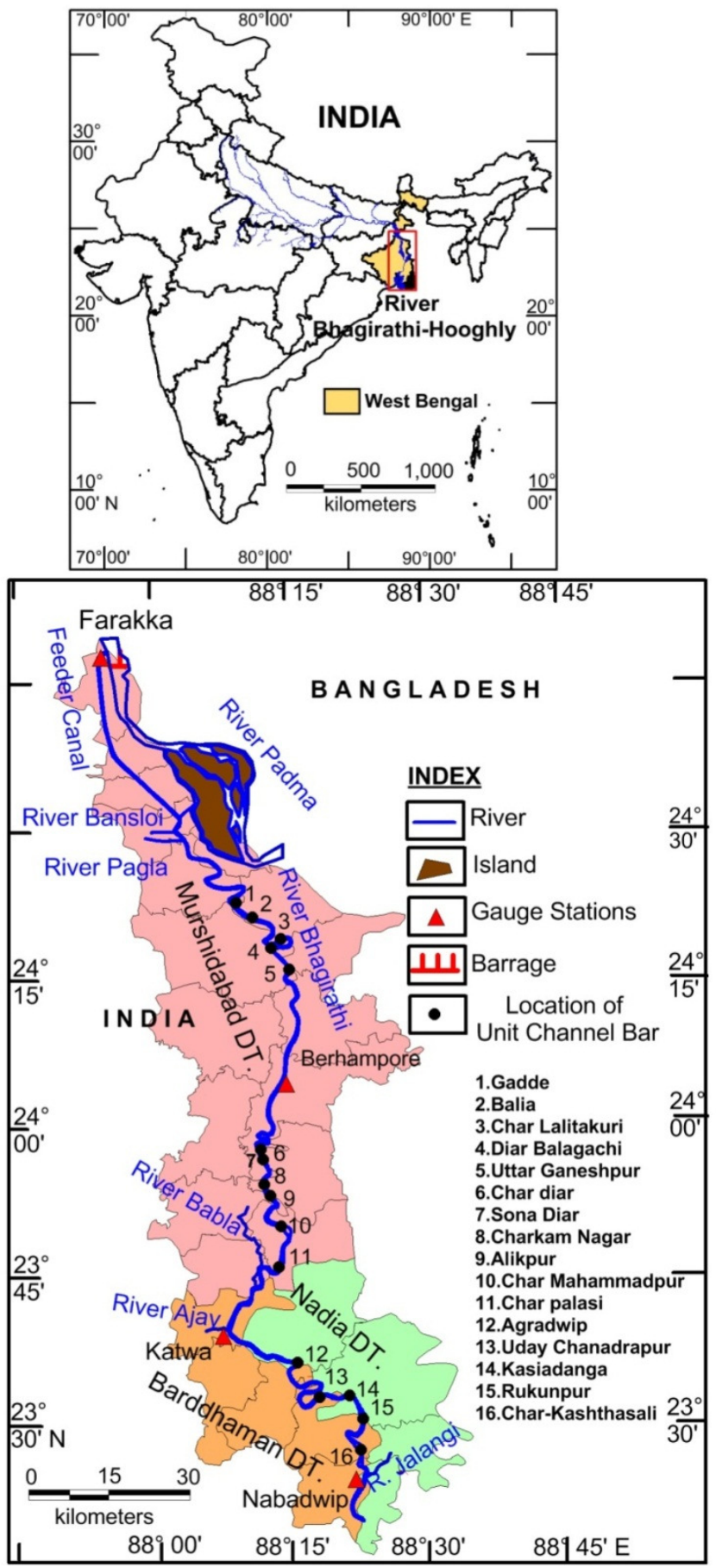

Fig. 2: Location of Unit Channel Bars on River Bhagirathi, India (Source: Google Earth Image, 2014)

\section{Results and Discussion}

First some theoretical possibilities and secondly some empirical observation from 
the field has been discussed. For discussion and elaboration of the derived indices a number of theoretical possibilities have been considered for the left bank orientation of the bar and right bank orientation of the bar separately. Physically a unit channel bar may be either attached to left bank or inclined towards left bank. It can be readily observed by determining the physical location of the bar within the channel. But the discharge consideration of the respective channels may distort this simple observation and a complex virtual location of the bar may deviate widely from the physical location of the bar. To show this deviation five cases have been considered. Firstly, when a bar attached to left bank and $100 \%$ discharge is through right part (Fig. $3 \mathrm{a}), \mathrm{L}_{\mathrm{b}} 1$ is equal to -1 and $\mathrm{Q}_{\mathrm{b}}=\left(\mathrm{Q}_{1}-\mathrm{Q}_{\mathrm{r}}\right) / \mathrm{Q}=$

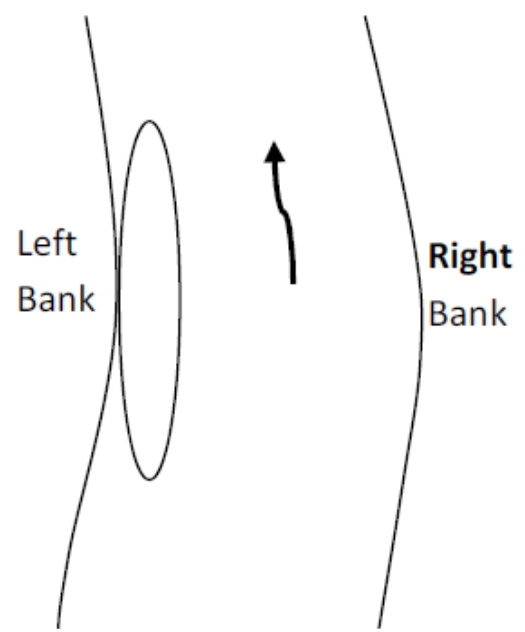

Fig. 3(a): Bar attached to left bank

Alternatively a unit channel bar may either be attached to right bank or oriented towards the right bank. The physical location of this bar will be on the right side of the channel (Fig. 4a and 4b) but virtual or relative location may vary widely
-1. So, the $\mathrm{L}_{\mathrm{b}} 2$ will be -1 . Secondly, when bar is towards left bank and $80 \%$ discharge is through right part and $20 \%$ through left part (Fig. 3b), $\mathrm{L}_{\mathrm{b}} 1$ and $\mathrm{Q}_{\mathrm{b}}$ is equal to - 0.8 and - 0.6 respectively. So the $\mathrm{L}_{\mathrm{b}} 2$ will be 0.7. Thirdly, when a bar is towards left bank and 20\% discharge is through right part and $80 \%$ through left part (Fig. 3b), $\mathrm{L}_{\mathrm{b}} 1$ and $\mathrm{Q}_{\mathrm{b}}$ is equal to -0.8 and 0.6 respectively. So the $\mathrm{L}_{\mathrm{b}} 2$ will be -0.1 . Fourthly, when a bar is towards left bank and 0\% discharge is through right part and $100 \%$ through left part (Fig. 3b), $\mathrm{L}_{\mathrm{b}} 1$ and $\mathrm{Q}_{\mathrm{b}}$ is equal to - 0.8 and 1 respectively. So the $\mathrm{L}_{\mathrm{b}} 2$ will be 0.1 . Fifthly, when a bar is towards left bank and $100 \%$ discharge is through right part and $0 \%$ through left part (Fig. 3b), $\mathrm{L}_{b} 1$ and $\mathrm{Q}_{\mathrm{b}}$ is equal to -0.8 and -1 respectively. So the $L_{b}$ 2 will be -0.9 .

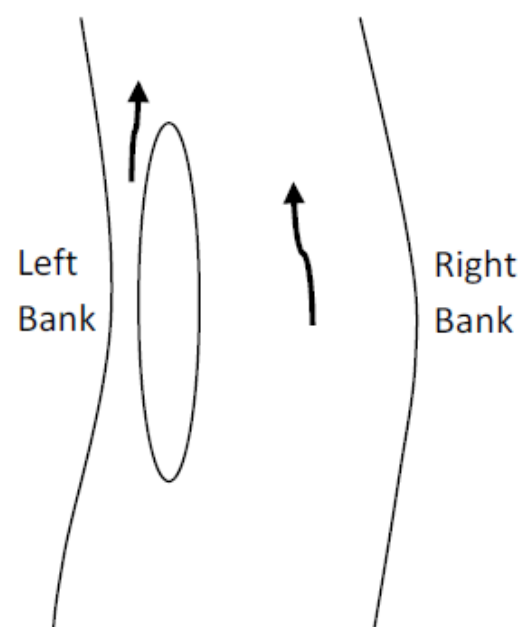

Fig. 3(b): Left bank oriented bar

depending upon the discharge of the respective channels. The five alternative results can be obtained following the same procedure as in case of the left bank orientation of the bar. 


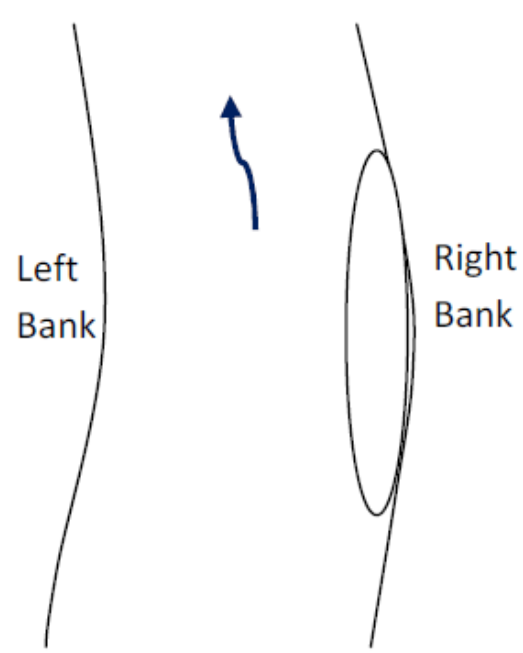

Fig. 4(a.): Bar attached to right bank

After the theoretical illustration, the indices have been applied to the real field data collected from the River Bhagirathi, West Bengal, India. It has been observed that out of 16 unit bars, only one left bank

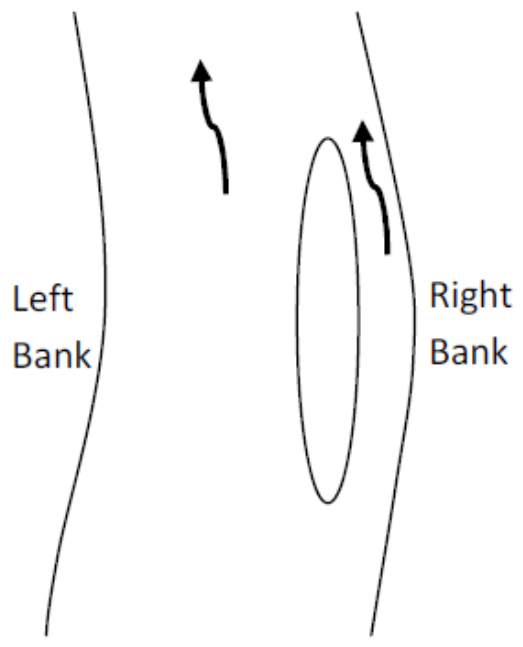

Fig. 4(b): Right bank oriented bar

attached and another two are right bank attached. No bar, having perfect mid channel condition, is found. Most of the bars are located within the range of 0.5 to 0.8 (Table 1and Fig. 5).

Table 1: Location of Unit Channel Bar of Bhagirathi River using $L_{b} 1$

\begin{tabular}{|c|c|c|c|c|c|c|}
\hline $\begin{array}{l}\text { Sl. } \\
\text { No. }\end{array}$ & $\begin{array}{l}\text { Name of the Unit } \\
\text { Channel Bar }\end{array}$ & $\mathrm{W}_{\mathrm{l}}$ (metre) & $\mathrm{W}_{\mathrm{b}}($ metre $)$ & $\mathrm{W}_{\mathrm{r}}($ metre $)$ & $\begin{array}{l}\mathrm{W} \\
\text { (metre) }\end{array}$ & $\mathrm{L}_{\mathrm{b}} 1$ \\
\hline 1 & Gadde & 241.97 & 158.67 & 93.00 & 493.64 & 0.62 \\
\hline 2 & Balia & 83.67 & 261.46 & 241.21 & 586.34 & -0.71 \\
\hline 3 & Char Lalitakuri & 35.55 & 123.02 & 255.12 & 413.69 & -0.83 \\
\hline 4 & DiarBalagachi & 322.91 & 292.37 & 82.02 & 697.3 & 0.76 \\
\hline 5 & Uttar Ganeshpur & 20.20 & 88.14 & 273.17 & 381.51 & -0.89 \\
\hline 6 & Char diar & 484.09 & 197.91 & 109.16 & 791.16 & 0.72 \\
\hline 7 & SonaDiar & 259.51 & 342.14 & 87.10 & 688.75 & 0.75 \\
\hline 8 & Charkam Nagar & 405.58 & 282.04 & 0.00 & 687.62 & 1.00 \\
\hline 9 & Alikpur & 324.66 & 214.37 & 0.00 & 539.03 & 1.00 \\
\hline 10 & Char Mahammadpur & 208.85 & 431.62 & 245.26 & 885.73 & -0.53 \\
\hline 11 & Char palasi & 221.96 & 205.69 & 156.60 & 584.25 & 0.46 \\
\hline 12 & Agradwip & 0.00 & 350.72 & 284.32 & 635.04 & -1.00 \\
\hline 13 & UdayChanadrapur & 353.35 & 275.84 & 166.55 & 795.74 & 0.58 \\
\hline 14 & Kasiadanga & 256.01 & 466.36 & 145.85 & 868.22 & 0.66 \\
\hline 15 & Rukunpur & 278.93 & 492 & 234.57 & 1005.5 & 0.53 \\
\hline 16 & Charkshthasali & 300.48 & 615.35 & 159.06 & 1074.89 & 0.70 \\
\hline
\end{tabular}




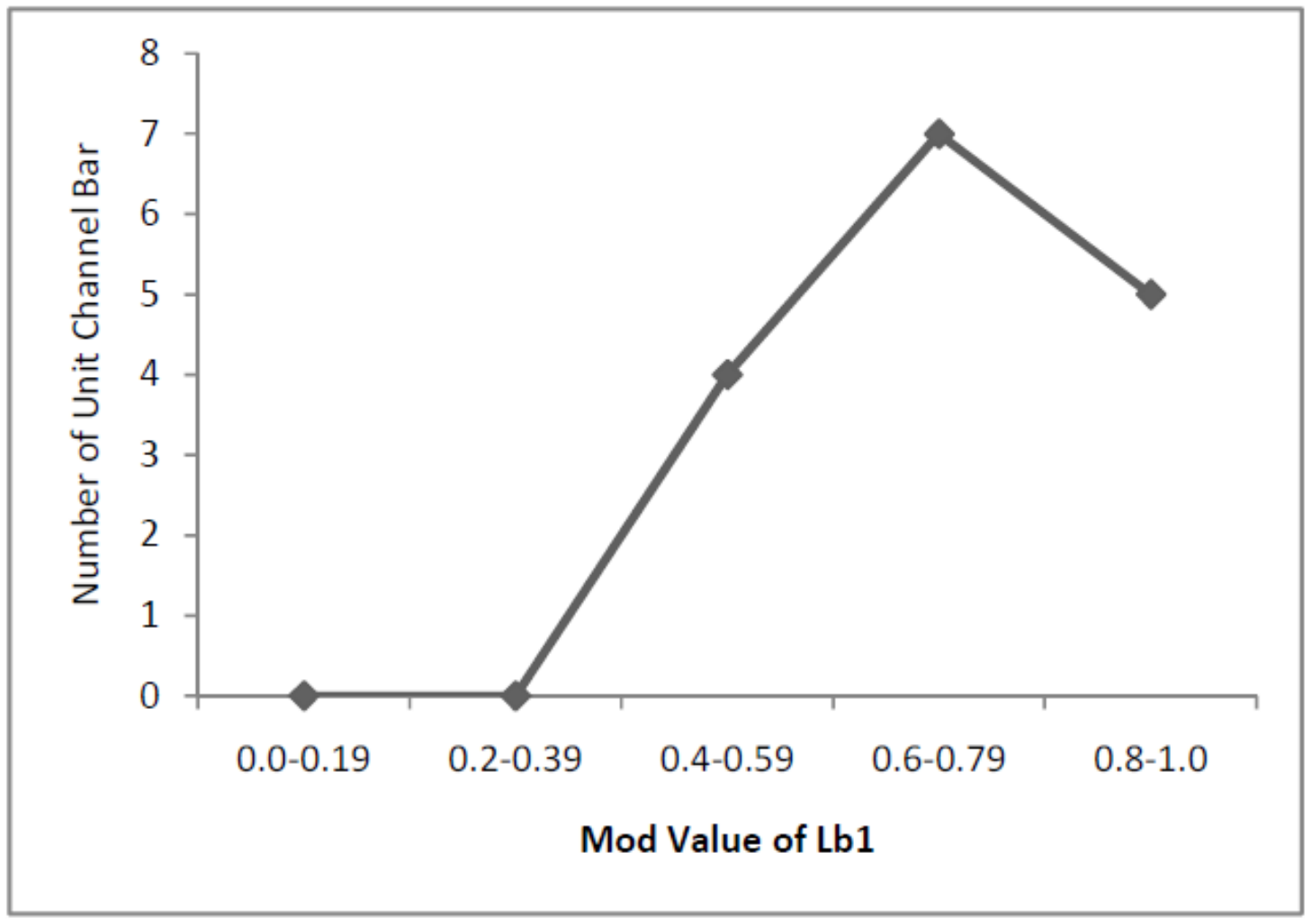

Fig. 5: Distribution of unit channel bar using $\mathrm{L}_{b} 1$

It indicates that majority of the bars are either towards left bank or towards right because of the presence of the asymmetric flow pattern.

\section{Conclusion}

Quantitative definition to unit channel bar location is perhaps unexplored till now. The indices proposed here is the new addition to the field of meandering channel morphology. These indices will also be able detect the changes in bar location and the conversion process of mid channel bar into abank attached bar. There is an ample scope to develop more indices to define location of unit and compound channel bar for both the meandering and braided streams on strict quantitative basis.

\section{References}

Ashmore, P.E. (1991). How do gravel-bed rivers braid? Can. J. Earth Sci., 28: 326-341.
Ashmore, P.E. (1982). Laboratory modelling of gravel, braided stream morphology. Earth Surf. Proc. Landforms, 7: 201-225.

Ashworth, P.J. (1996). Mid-channel bar growth and its relationship to local - ow strength and direction. Earth Surf. Proc. Landforms, 21: 103-123.

Ashworth, P.J., Best, J.L., Roden, J.E., Bristow, C.S. and Klaassen, G.J. (2000). Morphological evolution and dynamics of a large, sand braid-bar, Jamuna River, Bangladesh. Sedimentology, 47: 533-555.

Bristow, C.S. and Best, J.L. (1993). Braided rivers: perspectives and problems. In: Braided Rivers (Ed. by J.L. Best and C.S.Bristow). Spec. Publ. Geol. Soc., 75: 1-11.

Das, B.C. and Islam, A. (2015). Channel Asymmetry of an Ox-Bow Lake: A Different Perspective, International 
Journal of Ecosystem, 5(3A): 69-74 DOI: $10.5923 /$ c.ije. 201501.10

Knighton, A.D. (1981). Asymmetry of River Channel Cross-Sections: Part I. Quantitaive Indices. Earth Surface Processes and Landforms, 6: 581-588.

Knighton, D. (1984). Fluvial forms and Processes. Baltimore: Edward Arnold.

Leopold, L.B., Wolman, G. and Miller, J.P. (1964). Fluvial Processes in Geomorphology. New Delhi: Eurasia Publishing House (pvt.) Ltd.

Prus-Chacinski, T.M. (1954). Pattern of motion in open channel bends. Assoc. Internat. D'Hydrologie, 3: 311-318.

Charlton, R. (2008). Fundamentals of Fluvial Geomorphology. London and New York: Routledge.

Reineck, H.E. and Wunderlich, F. (1968). Zur Unterscheidung von asymmetrischen Oszillationsrippeln und Stromungsrippeln. Senckenbergiana Lethaea, 49: 321345.

Richards, K. (1982). Rivers: forms and process in alluvial channels. London: Methuen.

Smith, N.D. (1974). Sedimentology and bar formation in the upperKicking Horse River, a braided outwash stream. Journal of Geology, 82: 205-223.

Tanner, W.F. (1967). Ripple Mark Indices and their uses. Sedimentology, 9: 89104.

Thorne, C.R., Russell, A.P. and Alam, M.K. (1993). Planform pattern and channel evolution of the Brahmaputra River, Bangladesh. Spec. Publ. Geol. Soc., 257-276. 